\title{
Rainer Schröder
}

\section{Verwaltungsrechtsdogmatik im Wandel}

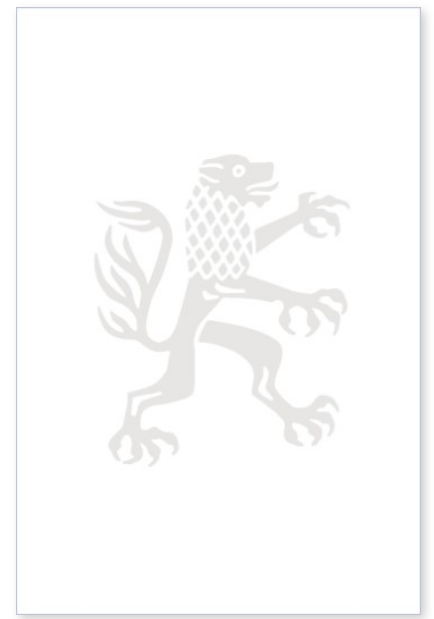

2007. XVII, 379 Seiten. JusPubl 166

ISBN 978-3-16-151247-6

DOI 10.1628/978-3-16-151247-6

eBook PDF $129,00 €$
Ist die Verwaltungsrechtswissenschaft in der Lage, gesellschaftliche Veränderungen ohne Verlust ihrer wissenschaftlichen Identität aufzunehmen? Rainer Schröder geht dieser Frage in drei Teilen nach:

Zunächst widmet er sich der Entstehung und frühen Entwicklung der Wissenschaft vom Verwaltungsrecht. Im zweiten Teil untersucht er den Funktionswandel der öffentlichen Verwaltung unter dem Grundgesetz. Über Art. 28 Abs. 1 GG erweisen sich hier zunächst Eingriffs- und Leistungsverwaltung verklammert. Art. 1 Abs. 3 und 3 Abs. 1 GG führen zur Figur der Selbstbindung der Exekutive und relativieren so administrative Freiheitsräume in den Bereichen des unbestimmten Rechtsbegriffs und Ermessens. Eine Revision der Lehre vom besonderen Gewaltverhältnis wird von einem

Risikoverwaltungsrecht begleitet. Das Recht der Planung löst Forderungen nach einem grundlegenden Methodenwandel aus, und die Phänomene der Europäisierung und Privatisierung leiten auch in der Verwaltungsrechtswissenschaft einen Rückzug des Staats ein.

Vor diesem Hintergrund setzt der Autor im dritten Teil zu einer Neujustierung der Verwaltungsrechtswissenschaft an. In Auseinandersetzung mit der wissenschaftlichen Debatte um die Reform des Allgemeinen Verwaltungsrechts überprüft er die verbleibende Relevanz der juristischen Methode der Verwaltungsrechtswissenschaft und erarbeitet abschließend Innovationen im Verhältnis von Öffentlichem Recht und Privatrecht, dem Recht der Verwaltungsorganisation und der Handlungsformenlehre. Dogmatische Leitunterscheidungen wie Staat und Gesellschaft, Innen und Außen, Privatrecht und Öffentliches Recht, Eingriff und Leistung werden dabei intakt gehalten.

Rainer Schröder Geboren 1964; Studium der Rechtswissenschaften, Politik, Philosophie und Germanistik an der Universität Münster; 1998 Promotion; 2006 Habilitation; derzeit Vertretung einer Professur für Öffentliches Recht, insbes. Verwaltungsrecht, Verwaltungswissenschaften und Rechtsvergleichung an der TU Dresden.

Jetzt bestellen:

https://mohrsiebeck.com/buch/verwaltungsrechtsdogmatik-im-wandel-9783161512476?no_cache=1 order@mohrsiebeck.com

Telefon: +49 (0)7071-923-17

Telefax: $+49(0) 7071-51104$ 